\title{
The impact of a volunteer-led community cancer awareness programme on knowledge of cancer risk factors and symptoms, screening, and barriers to seeking help \\ DOI:
}

10.1016/j.pec.2019.09.025

Document Version

Accepted author manuscript

Link to publication record in Manchester Research Explorer

Citation for published version (APA):

Williams, G., Mueller, J., Mbeledogu, C., Spencer, A., Parry-Harries, E., Harrison, A., Clough, G., Greenhalgh, C., $\&$ Verma, A. (2019). The impact of a volunteer-led community cancer awareness programme on knowledge of cancer risk factors and symptoms, screening, and barriers to seeking help. Patient education and counseling. https://doi.org/10.1016/j.pec.2019.09.025

Published in:

Patient education and counseling

\section{Citing this paper}

Please note that where the full-text provided on Manchester Research Explorer is the Author Accepted Manuscript or Proof version this may differ from the final Published version. If citing, it is advised that you check and use the publisher's definitive version.

\section{General rights}

Copyright and moral rights for the publications made accessible in the Research Explorer are retained by the authors and/or other copyright owners and it is a condition of accessing publications that users recognise and abide by the legal requirements associated with these rights.

\section{Takedown policy}

If you believe that this document breaches copyright please refer to the University of Manchester's Takedown Procedures [http://man.ac.uk/04Y6Bo] or contact uml.scholarlycommunications@manchester.ac.uk providing relevant details, so we can investigate your claim.

\section{OPEN ACCESS}




\section{Journal Pre-proof}

The impact of a volunteer-led community cancer awareness programme on knowledge of cancer risk factors and symptoms, screening, and barriers to seeking help

Greg Williams, Julia Mueller, Cordelle Mbeledogu, Angela Spencer,

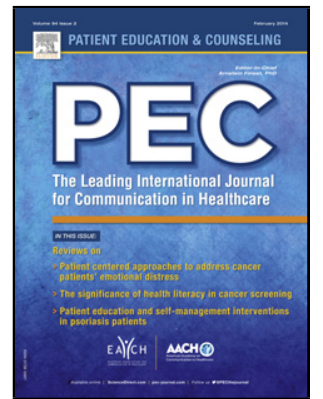
Emily Parry-Harries, Annie Harrison, Gary Clough, Christine

Robinson, Arpana Verma

PII:

DOI:

Reference:

To appear in:

Received Date:

Revised Date:

Accepted Date:
S0738-3991(18)30540-8

https://doi.org/10.1016/j.pec.2019.09.025

PEC 6412

Patient Education and Counseling

10 August 2018

20 August 2019

24 September 2019

Please cite this article as: Williams G, Mueller J, Mbeledogu C, Spencer A, Parry-Harries E, Harrison A, Clough G, Robinson C, Verma A, The impact of a volunteer-led community cancer awareness programme on knowledge of cancer risk factors and symptoms, screening, and barriers to seeking help, Patient Education and Counseling (2019), doi: https://doi.org/10.1016/j.pec.2019.09.025 
This is a PDF file of an article that has undergone enhancements after acceptance, such as the addition of a cover page and metadata, and formatting for readability, but it is not yet the definitive version of record. This version will undergo additional copyediting, typesetting and review before it is published in its final form, but we are providing this version to give early visibility of the article. Please note that, during the production process, errors may be discovered which could affect the content, and all legal disclaimers that apply to the journal pertain.

(C) 2019 Published by Elsevier. 


\section{The impact of a volunteer-led community cancer awareness programme on knowledge of cancer risk factors and symptoms, screening, and barriers to seeking help}

Greg Williams*, Julia Mueller*, Cordelle Mbeledogu**, Angela Spencer*, Emily Parry-Harries ${ }^{* * *}$, Annie Harrison*, Gary Clough*, Christine Robinson* and Arpana Verma*

*University of Manchester, Manchester Urban Collaboration on Health, Room 2.525 Stopford Building, Oxford Road, Manchester, M13 9PT

Email addresses: greg.williams@manchester.ac.uk, julia.mueller@manchester.ac.uk, Angela.Spencer@manchester.ac.uk, annie.harrison@manchester.ac.uk. Gary.Clough@manchester.ac.uk, Christine.A.Robinson@manchester.ac.uk, Arpana.Verma@manchester.ac.uk

** Manchester City Council \& North Manchester CCG, Manchester City Council, Directorate of Children and Families, Public Health Team, Level 4, PO Box 532, Town Hall Extension, Manchester, M60 2LA

Email Address: c.mbeledogu@manchester.gov.uk

${ }^{* * *}$ Kirklees Council, Civic Centre, $4^{\text {th }}$ Floor North, High Street, Huddersfield, HD1 2NF

Email Address: Emily.Parry-Harries@kirklees.gov.uk

Corresponding author:

Greg Williams, Room 2.525 Stopford Building, University of Manchester, Oxford Road, Manchester, M13 9PT

Telephone number: +44 (0)161306 0698

Email address: greg.williams@manchester.ac.uk 
The impact of a volunteer-led community cancer awareness programme on knowledge of cancer risk factors and symptoms, screening, and barriers to seeking help

\section{Highlights}

- Community awareness campaigns can help lower perception of barriers to seeking help

- Messages perceived as personally relevant may improve information processing

- Participants were more likely to recognise warning signs than recall warning signs

\section{Abstract}

Objective

To analyse the impact of a community cancer awareness programme on knowledge of cancer risk factors and symptoms, screening, and barriers to seeking help.

Methods

Personalised information through peer-led champions was delivered to 5,500 people in a range of settings and Cancer Awareness Measures questionnaires were completed by 119 participants at prearranged sessions (convenience sampling) before and after the intervention. Data were analysed using McNemar tests, Mann-Whitney U-test and a Wilcoxon Signed Rank test.

Results

Data showed increase in knowledge after the intervention for cancer screening programmes $(p<0.05)$, recognition of warning signs for cancer $(p<0.05)$, and recognition of risk factors for cancer in seven of the eleven options $(p<0.001)$. Results suggest a decrease in perception of barriers to seeking help $(p<0.05)$. The intervention had a stronger impact on recognition of cancer symptoms for people who have been affected by cancer $(p=0.02)$.

Conclusion

The Cancer Awareness Measures questionnaire proved an effective tool for evaluation and awareness improved after the intervention amongst those who completed it. 
Practice Implications

Enhancing the perceived personal relevance of information to those with experience of cancer may improve information processing and retention. The study highlights cancer awareness gaps among the public for future intervention development.

\section{Key Words}

Cancer Awareness, cancer symptoms, cancer risk factors, barriers to help seeking, delays to help seeking 


\section{Introduction}

Cancer remains a worldwide burden [1]. The burden of disease increases as the population ages, and changes in age distribution mean incidence will continue to rise despite progress, reducing mortality rates [2]. United Kingdom (UK) patients have more advanced stage of disease at diagnosis compared to other European countries [3]. Diagnostic delays and advanced stage at diagnosis contribute to poor survival [4] and the UK has lower cancer survival rate than the European average [5].

Awareness of many warning signs for cancer is low in England [6]. Increasing awareness of signs and symptoms of disease could result in earlier diagnosis [7-14]. A previous awareness-raising campaign regarding bowel cancer, for example, resulted in a 50\% increase in attendance at GP surgeries for symptoms highlighted in the campaign [15].

Individuals from socio-economically deprived areas as well as other hard-to-reach groups such as ethnic minorities and people with learning disabilities can be particularly vulnerable to risk factors and delays to diagnosis [12-17]. To effectively reach and engage these vulnerable high-risk populations, cancer awareness interventions can use lay health volunteers recruited from the target population to deliver and disseminate intervention information. By providing cultural understanding and relevant experience, these volunteers can successfully engage marginalised, vulnerable groups [18-20].

Another important strategy in delivering health information is enhancing perceived personal relevance [21]. Information perceived as personally relevant is more likely to impact on health behaviour [22]. In large-scale interventions it is difficult to present information tailored to individual needs and characteristics due to limited resources, which may reduce effectiveness, as health messages perceived as generic may be dismissed as irrelevant [23]. A simple way of enhancing perceived personal relevance may be to highlight personal experiences individuals have had with the disease. This approach may be particularly feasible in cancer awareness endeavours as approximately one in two people will develop cancer at some point, suggesting the majority of 
people have been personally affected by the disease [24]. Thus, it is important to assess whether those who report being affected by cancer previously respond differently to cancer awareness interventions than those who report not being previously affected [24].

Using a community-based approach, the "Let's be clear, get it checked!" intervention aimed to increase awareness of breast, bowel and lung cancer in two areas of Northern England (Manchester and Tameside \& Glossop). Seventy-eight volunteers were recruited and trained to disseminate cancer awareness information within local communities. The evaluation focused on assessment of the delivery, satisfaction and acceptability, impact on cancer awareness, and the impact of the intervention on early diagnosis for cancer in Manchester and Tameside \& Glossop. For the pre-arranged sessions, following a literature review and assessment of validated cancer awareness measuring tools, the Cancer Awareness Measure (CAM) was found to be the most appropriate tool for pre- and post- evaluation of the impact of the intervention on cancer awareness [25]. The CAM was developed in 2009 in response to challenges of measuring cancer awareness as noted by Stubbins et al, such as lack of consistency in question format and therefore, inability to make cross-study comparisons [3]. The CAM is a widely used and validated measure to assess cancer awareness.

The aim of this study is to evaluate the impact of a community-based cancer awareness raising programme on cancer knowledge and awareness of those who received the intervention. In particular, this study aims to examine knowledge of cancer symptoms, risk factors, and screening programmes, anticipated delay in seeking medical advice, and barriers to seeking medical advice, before and after the intervention. We also aimed to assess whether the intervention had differing effects on those who have been personally affected by cancer (i.e. because either they, or someone they know, was previously diagnosed with cancer), than those who have not been personally affected. 


\section{Methods}

\section{Intervention}

The intervention involved personalised information delivered by Macmillan employees and volunteers around the two areas, between September 2012 and March 2015. It included information on signs and symptoms, screening programmes, susceptibility, and prevalence of breast, bowel and lung cancer, whilst acknowledging barriers to early diagnosis. The intervention generally covered risk factors, but it was not the main focus of the intervention so were not covered in some instances. Members of the public were signposted to mainstream services and encouraged to attend GP appointments if signs or symptoms of cancer were recognised. Interventions were delivered in a variety of formats, and where appropriate, information delivery included: Leaflets (e.g. Macmillan, Be clear on cancer), PowerPoint presentation, and games quiz, signs and symptoms cards, inflatable bowel tour, and a box of symptoms. Macmillan staff members offered personal one-to-one talks as part of the intervention that were considerate of those with experience of cancer if the participant addressed this. The focus of the intervention was on people over 50 years of age and hard to reach groups, primarily Black, Asian and minority ethnic groups, in the most deprived areas of Manchester and Tameside \& Glossop, where cancer outcomes were poor and screening uptake was low. The intervention was conducted in a number of settings linked to the target groups, including community groups or identified events, prearranged sessions (requested by businesses for their employees to attend on the business's premises), and stalls at local events and places of interest (e.g. individual businesses, pubs and community centres). Although the locations were chosen based upon the target group, nobody was excluded from receiving the intervention. This study focuses on the findings from the CAM questionnaire, which were only delivered at pre-arranged sessions. A Template for Intervention Description and Replication (TIDieR) can be found in Appendix A.

\section{Recruitment and training}


For delivery of the intervention there was a focus on recruiting volunteers from areas of high deprivation, and no formal qualifications were required to volunteer. A total of 78 volunteers were recruited across two target areas through leaflets, existing services and a snowballing technique [26]. They were given two-day training sessions, delivered by Macmillan health promotion champions, during which they were given information on signs and symptoms of breast, bowel and lung cancer, and were trained in public engagement. Volunteers gained accredited health promotion training tailored to their level of knowledge and confidence.

\section{Data collection}

The full intervention was delivered to at least 5,500 people (3,579 in Manchester, and 1,921 in Tameside \& Glossop, based on completion of a brief satisfaction questionnaire). Brief evaluation surveys were administered in all settings, whilst CAM questionnaires were only used in prearranged group sessions using convenience sampling to maximise the number of people completing the CAM post-intervention. The number of participants at pre-arranged sessions was transitory and therefore not possible to measure.

The generic CAM, consisting of nine questions with a total of 47 items, was used to establish cancer knowledge before and after the intervention [27]. Participants completed a demographic questionnaire and a first copy of the CAM questionnaire prior to the intervention, and a second copy of the CAM immediately afterwards (all face-to-face). The intervention was conducted by Macmillan staff members, who also helped any participants that needed assistance filling in their questionnaires where appropriate due to disability and language issues. Staff members were trained not to influence the participants' responses to minimise reporting bias. All CAM data were uploaded to the UK Data Archive in accordance with the Cancer Awareness Measure (CAM) Toolkit version 2.1. [27]

Data analysis

Data were entered into Microsoft Excel 2010 before being cleaned, recoded and analysed using IBM SPSS Statistics 20.0. [28, 29] Coding and scoring of the data was done according to CRUK's 
guidance [27]. Descriptive statistics, allowing for directional comparisons, were also conducted. Paired categorical data were analysed using a McNemar test, and paired ordinal data were analysed using the Wilcoxon Signed Rank test, to determine the statistical significance of the differences between the participants' responses before and after the intervention. The nonparametric Mann-Whitney U-test was used for comparisons between independent groups for continuous variables (because data were non-normally distributed), and the chi-square test was used for categorical variables.

Data were analysed for all 9 questions, which covered warning signs of cancer, how soon a participant would contact a doctor with a symptom, barriers to seeking help, cancer risk factors, knowledge of cancer, and knowledge of screening programmes.

Questions 1 and 5 were open, and were coded into pre-defined binary categories for analyses. Reponses to an open question about what participants thought were the three most common cancers in men and women (question 8) were coded according to the number of correctly identified cancers (regardless of the order they were listed in).

The answers to a closed question asking about barriers to seeking help (question 4) were dichotomised (coded to yes/no). Similarly, for an open question asking what age the participant thought people were first invited for screening (question 9), answers were dichotomised to correct/incorrect (allowing for \pm 5 years, because breast and bowel cancer screening ages span several years).

\section{Results}

119 participants completed the demographical survey and the CAM both before and after the intervention. Of those who responded to the questionnaire, $79 \%$ (94/119) were female, $76.3 \%$ (90/118) identified themselves as White British, 90.7\% (107/118) stated that English was their first language, $79.8 \%(75 / 94)$ achieved O-Level/GCSE grades A-C or above as their highest 
educational attainment, and $71.8 \%(84 / 117)$ stated that they had a friend of family member who had experienced cancer (Table 1).

\section{Knowledge of warning signs and risk factors}

Table 2 shows responses for warning signs and risk factors of cancer that participants could recall or recognise before and after the intervention. When asked to recall warning signs for cancer, 'Bleeding', 'Cough/hoarseness', 'change in bowel/bladder habits', 'change in appearance of a mole', and 'weight loss' all showed significant improvements in the number of times mentioned after the intervention $(p<0.001)$. 'Lump/swelling' showed no significant difference after, but it was the highest response both before $(n=107)$ and after $(n=106)$.

When asked to recognise warning signs of cancer, all options showed a statistically significant improvement in the number of correct answers after $(p<0.05)$ except for lump/swelling and change in appearance of mole. However, all of the variables showed an improvement with at least $90 \%$ getting the answer correct after the intervention.

When asked to recall risk factors for cancer, the majority of variables showed no significant difference between responses before and after. However, being overweight $(p=0.031)$, diet $(p=0.019)$ and older age $(p=0.008)$ all showed significant differences with more people mentioning them afterwards. Not doing enough exercise/physical activity showed a negative significant difference $(p<0.001)$ with a decline in responses after the intervention from five to zero.

All responses for recognising risk factors saw a significant improvement in how participants responded after, except for smoking $(p=0.453)$, passive smoking $(p=0.180)$ and having a close relative with cancer $(\mathrm{p}=0.344)$. Of these, only smoking decreased after the intervention $(\mathrm{n}=48$ to $\mathrm{n}=45$ ), however this was still the most recognised risk factor.

Participants who reported knowing someone with cancer were compared against those who reported not knowing anyone diagnosed with cancer. Post-intervention, those reportedly affected by cancer previously $(n=84)$ recalled on average 0.44 risk factors more than pre-intervention, 
compared to 0.24 among those reportedly not affected $(n=33)$, but this difference was not significant $(U=1284.0, Z=-0.70, p=0.48)$. Those reportedly affected by cancer showed a larger increase in recognition of cancer risk factors from before to after the intervention (Mean=1.37) than those not affected (Mean=0.39); this difference was significant $(U=1047, Z=-2.36, p=0.02)$. There was no significant association between being affected/not affected by cancer and reporting delay/no delay post intervention $\left(x(1)^{2}=1.67, p=0.2\right)$.

\section{Barriers and delay}

When asked how soon they would contact the doctor if they had a symptom they thought was a sign of cancer, the McNemar Test showed no significant difference $(p=0.063)$ between there being "no delay" before and after. However, there was an improvement from $90.7 \%(98 / 108)$ to $95.5 \%$ $(106 / 111)$ of participants indicating that there would be no delay after the intervention.

Table 3 shows the results of the McNemar Test on the dichotomised values for barriers to seeking help. All responses showed a statistically significant difference between before and after values $(p<0.05)$, with respondents showing a decrease in perception of barriers to seeking help for all provided responses after the intervention. Being worried about what the doctor would find and being scared were the most common barriers to seeking help both before $(64 \%$ and $58.4 \%$ respectively) and after (31.9\% and $28.2 \%)$. The least common barriers before the intervention were difficulty in arranging transport (22.5\%) and difficulty in talking to a doctor (25\%), with being worried about wasting time $(6.9 \%)$ and being too busy $(8.6 \%)$ the least common barriers to seeking help after the intervention.

Figure 1 demonstrates the fall in all responses for barriers to seeking help after the intervention. The biggest decrease in responses were for being worried about what the doctor would find, which went down from $64 \%$ to $31.9 \%$ after the intervention, and being scared, which went down from $58.4 \%$ to $28.2 \%$. 
There was no significant difference in the decrease of the reported number of barriers to helpseeking between those affected and those not affected (Mean=-1.90 and Mean=-1.88 respectively, $U=1339, Z=-0.29, p=0.77)$.

\section{Knowledge of cancer and services}

When asked about what age people were most likely to develop cancer, the McNemar test found no significant difference between before and after ( $p>0.999)$. The majority of respondents chose the option "Cancer is unrelated to age" for both before and after the intervention, with 95 (83.3\%) choosing this option before and 95 (85.6\%) choosing it after.

Table 4 shows the results of the Wilcoxon Signed Rank test for naming the three most common cancers, demonstrating that the participants' knowledge improved significantly. The test showed 77 out of the 119 respondents increased the number of correct answers for the most common female cancers, with 36 remaining the same and 6 lowering the number they got correct $(Z=-$ 7.004, $\mathrm{p}<0.001$ ). For male cancers, the test showed an increase in 75 respondents, with 39 remaining the same and 5 reducing the number they got correct $(Z=-6.843, p<0.001)$.

When questioned whether respondents were aware that there was a screening programme for breast, cervical and bowel cancer, the McNemar Test showed a statistically significant difference between before and after awareness for breast cancer screening, with 102 respondents (88.7\%) answering correctly before and 114 respondents (98.3\%) after $(p=0.007)$. Awareness of cervical cancer screening showed a significant difference $(p=0.021)$ with 103 correct answers before (90.4\%) and 111 after (97.4\%), and bowel cancer screening awareness also showed a significant difference $(\mathrm{p}=0.003)$ with 90 correct answers before $(79.7 \%)$ and 105 after $(92.1 \%)$.

Respondents who got the correct age for first invitations ( \pm 5 years) for breast cancer screening improved significantly, with $47(60.3 \%)$ correctly identifying before the intervention, and $88(93.6 \%)$ after $(p<0.001)$. Bowel cancer screening age estimates also improved significantly from 32 $(47.8 \%)$ before, to $77(90.6 \%)$ after $(p<0.001)$. There was an improvement in responses for the 
first cervical cancer screening invitations from 61 (76.3\%) before to 73 (85.9\%) after, but this was not statistically significant $(p=0.210)$.

\section{Discussion and Conclusion}

\subsection{Discussion}

Knowledge of risk factors and warning signs indicated statistically significant knowledge improvement. Following the intervention, over $90 \%$ of participants were able to recognise the warning signs of cancer provided in the questionnaire. Although their ability to recall warning signs was lower, recognising warning signs is more important as the patient will need to recognise a symptom as a prompt to seek care [30], and not recognising a symptom can lead to delays in seeking help [31].

Results of the before questionnaire can also help identify knowledge gaps in the population, which could be used to develop future interventions. For example, when asked to write what they thought were warning signs of cancer, the respondents averaged only 3-4 answers before the intervention. Table 2 clearly highlights gaps in knowledge that need to be addressed. Four out of the five highest number of responses for this question before the intervention were the same in an Ethnibus survey $(n=1,500)$, and three out of the five highest in an ONS Opinions Survey $(n=2,216)$ that asked the same question [30].

Those who reported knowing someone who had previously been diagnosed with cancer showed a larger increase in the number of cancer risk factors they recognised than those who did not. Possibly, those who reported knowing someone diagnosed with cancer subsequently perceived the information presented in the intervention as more personally relevant than those who reported not being previously affected by cancer. The Elaboration Likelihood Model (ELM) propounds that information can be processed "centrally" or "periphally" [32]. According to the model, information is more likely to be carefully considered, remembered and lead to long-term changes in attitude and behaviour if it is processed centrally [33]. Individuals are more likely to process information 
centrally if it is perceived as personally relevant. This study presents preliminary evidence suggesting that one strategy for improving cancer symptom recognition may be to highlight individuals' previous personal experiences with cancer.

The questionnaires were able to demonstrate that after the intervention more of the participants were aware of the NHS screening programmes after the intervention. Awareness of bowel cancer screening before the intervention $(79.65 \%)$ was higher than a European study which found that only $51 \%$ of participants studied were aware of bowel cancer screening [34].

Results suggested that the majority of participants would not delay visiting a doctor if they experienced symptoms $(90.7 \%$ before and $95.5 \%$ after $)$. This is in contrast to findings from an American study that investigated delays in patients seeking medical advice for breast cancer, which found that $52.9 \%$ of patients delayed seeking medical advice, citing multiple reasons for the delay such as financial problems and personal commitments [35]. Further investigation could be undertaken to understand the difference between populations and delay in seeking help.

When asked about what barriers there may be to the participant seeking advice, there were significant improvements after. Worrying about what the doctor might find was the most frequently mentioned barrier to seeking medical advice $(61.21 \%$ before, $31.9 \%$ after $)$, which was the same for another study that used CAM questionnaires to study awareness amongst ethnic minority groups in England [8].

Perception of barriers to seeking help was significantly reduced for all provided responses after the intervention. This demonstrates the importance of targeted campaigns and interventions for improving cancer survival through removal of barriers to increase early presentation, as discussed in other studies $[6,36]$. These studies did not measure the association between lack of knowledge of warning signs and delay to seeking medical advice; however, other studies have found that not recognising symptoms is a contributing factor to delay $[31,37]$. The results of the questionnaires showed that the intervention significantly improved knowledge of cancer awareness. Knowledge is 
seen as a necessary factor for behaviour change [38, 39] and a lack of knowledge could reduce the likelihood of someone participating in a screening programme [40].

\section{Limitations and future research}

The majority of CAMs were completed by female participants $(79.0 \%)$, in line with response rates from other studies [41, 42], thus findings may not be representative of male respondents. Engaging with men is of particular importance as there is evidence suggesting that men in the UK are diagnosed at a later stage for several cancers [43]. Although the locations were chosen to target over 50s and the hard-to-reach, as no one was excluded from the intervention, there were less older participants (41.5\% were 50 or above), who may be more appropriate for the intervention as cancer risk increases with age [27]. Selection bias may also have been introduced as the volunteers may not have been able to offer the CAM to all attendees due to logistical reasons (e.g. time, number of attendees).

The evaluation of the CAMs highlighted problems in the design of the tool that could be addressed in future studies. When asked how long it would take for a participant to see a doctor if they thought they had a symptom of cancer, the coding framework measures anything above one week as a delay and less than one week as no delay. However, the question is open-ended and so applying temporality is subjective on the person coding the data and does not take into account the participant's opinion of timescales. For example, we coded "ASAP" as having no delay, but the participant could define ASAP as being within a month, which would have been coded as having a delay according to the framework. The quality and accuracy of the results could be improved by using a closed question with options, or clearer instructions for the participants.

The study demonstrated no difference in the amount of people who knew the age that people were most likely to get cancer. The results for this question showed a clear pattern, with the majority of participants choosing the option "Cancer is unrelated to age" over the age bands given. If this option was removed, we may gain a clearer indication of the level of knowledge. In addition, the 
coding framework was ambiguous, stating the correct answer is "the oldest age shown", which would have implications depending on how many age categories were used.

The CAMs demonstrated that the intervention improved knowledge and awareness of symptoms, risks, barriers and NHS screening programmes. However, the timeframe with which the postintervention questionnaires were completed does not demonstrate the level of retention of knowledge, and whether or not it would change care-seeking behaviour in participants over an extended time period, as the first questionnaires were completed immediately before the intervention, and the second ones immediately after. A randomised control trial with a one-year follow-up, assessing knowledge retention about prostate cancer screening, found that although knowledge had fallen from the two week follow up, knowledge in the intervention group was higher than the control group one year later [44]. Further research would be required to determine lasting retention of knowledge and whether the intervention had a significant impact on the participants' behaviour and attitudes to cancer symptoms, risks and care-seeking.

Locally, this intervention was delivered shortly after a 'Don't be a Cancer Chancer' campaign [45] and local promotion of a national "Be Clear on Cancer" campaign [46]. These campaigns may have caused contamination bias in the knowledge of the participants before the intervention and in their recognition of the information delivered during the intervention.

Secondary analysis could also be conducted to analyse the findings and the demographics of participants. A study using CAM data to investigate the effectiveness of a "Be Clear on Cancer" campaign found no significant interaction between the results after the campaign and gender, age, ethnicity, occupation or cancer experience [36]. However, analysis of the Ethnibus sample did show differences in responses for gender, age and ethnicity, so whilst there may not be useable findings in a before and after study investigating the demographics of the responses, there could be merit in a stand-alone investigation to assess knowledge differences between different population groups [30]. 


\subsection{Conclusions}

CAMs have been used for assessing cancer knowledge and awareness. Pre-intervention CAMs can be used for designing future interventions addressing and targeting knowledge gaps. For future assessments it could be useful to administer the post-intervention questionnaire a significant amount of time after the intervention to assess knowledge retention, or a third follow-up questionnaire could be implemented into any future study.

\subsection{Practice Implications}

This study provides preliminary evidence that the intervention was more effective among those who report being affected by cancer. This finding may be useful in the development of future interventions, highlighting a possible means to enhance perceived personal relevance of information and thus information processing and retention. However, this requires further investigation prior to implementation in practice.

To improve the likelihood of knowledge retention, it would be recommended for the intervention to be repeated on the same sample of people periodically. If the intervention was delivered more than once, with brief reminders being issued from time to time, this could be more beneficial for when the participants have to make decisions on whether to attend screening [44].

\section{Additional Information}

\section{Ethics approval and consent to participate}

The protocol and evaluation tools were approved by the University Research Ethics Committee (UREC) at The University of Manchester and accepted for use within Manchester, and Tameside \& Glossop with complete indemnity cover (UREC number: 12297).

Further approval was required from the National Research Ethics Service (NRES) and the researchers submitted an Integrated Research Ethics System (IRAS) dataset (project ID: 116584), 
the protocol, and evaluation tools to the NRES Committee North West - Cheshire and received endorsement (REC reference: 12/NW/0886).

In advance of completing the CAM questionnaires, participants were asked to read through a participant information sheet which detailed the scope and purpose of the evaluation and then, if they agreed to take part, would then sign a consent form.

\section{Consent for publication}

Not applicable

\section{Availability of data and material}

All data for the study is housed at The University of Manchester. Please contact the corresponding author for further details.

\section{Conflict of interest}

All authors have no conflicts of interest to declare.

\section{Funding}

The evaluation of the campaign was funded by Macmillan Cancer Support and Christie Hospital NHS Foundation Trust.

\section{Authors' contributions}

G Williams conducted the analysis and wrote the manuscript.

"I confirm all patient/personal identifiers have been removed or disguised so the patient/person(s) described are not identifiable and cannot be identified through the details of the story."

$\mathrm{J}$ Mueller helped with the analysis and helped write the manuscript.

"I confirm all patient/personal identifiers have been removed or disguised so the patient/person(s) described are not identifiable and cannot be identified through the details of the story." 
C Mbeledogu coordinated the evaluation report and helped write the manuscript.

"I confirm all patient/personal identifiers have been removed or disguised so the patient/person(s) described are not identifiable and cannot be identified through the details of the story."

A Spencer helped write the manuscript.

"I confirm all patient/personal identifiers have been removed or disguised so the patient/person(s) described are not identifiable and cannot be identified through the details of the story."

E Parry-Harries helped write the manuscript.

"I confirm all patient/personal identifiers have been removed or disguised so the patient/person(s) described are not identifiable and cannot be identified through the details of the story."

A Harrison helped write the manuscript.

"I confirm all patient/personal identifiers have been removed or disguised so the patient/person(s) described are not identifiable and cannot be identified through the details of the story."

G Clough coordinated the data collection and helped write the manuscript.

"I confirm all patient/personal identifiers have been removed or disguised so the patient/person(s) described are not identifiable and cannot be identified through the details of the story."

C Robinson helped write the manuscript.

"I confirm all patient/personal identifiers have been removed or disguised so the patient/person(s) described are not identifiable and cannot be identified through the details of the story."

A Verma was the Principal Investigator and helped write the manuscript.

"I confirm all patient/personal identifiers have been removed or disguised so the patient/person(s) described are not identifiable and cannot be identified through the details of the story."

\section{Acknowledgements}


Thanks to Macmillan Cancer Support and Christie Hospital NHS Foundation Trust for funding the evaluation.

\section{References}

[[1] J. Ferlay, H.-R. Shin, F. Bray, D. Forman, C. Mathers, D.M. Parkin, Estimates of worldwide burden of cancer in 2008: GLOBOCAN, Int. J. Cancer 127 (2010) 2893-2917. 
[2] P. Boyle, J. Ferlay, Cancer incidence and mortality in Europe, 2004, Ann. Oncol. 16 (2005) 481-488.

[3] S. Stubbings, K. Robb, J. Waller, A. Ramirez, J. Austoker, U. Macleod, S. Hiom, J. Wardle, Development of a measurement tool to assess public awareness of cancer, Br. J. Cancer 101 Suppl 2 (2009) S13-S17.

[4] M.A. Richards, The size of the prize for earlier diagnosis of cancer in England, Br. J. Cancer 101 Suppl 2 (2009) S125-S129.

[5] M.P. Coleman, G. Gatta, A. Verdecchia, J. Estève, M. Sant, H. Storm, C. Allemani, L. Ciccolallo, M. Santaquilani, F. Berrino, EUROCARE-3 summary: cancer survival in Europe at the end of the 20th century, Ann. Oncol. 14(Suppl 5) (2003) 128-49.

[6] M. Niksic, B. Rachet, F.G. Warburton, J. Wardle, A.J. Ramirez, L.J. Forbes, Cancer symptom awareness and barriers to symptomatic presentation in England--are we clear on cancer?, Br. J. Cancer 113(3) (2015) 533-42.

[7] N. Brunswick, J. Wardle, M.J. Jarvis, Public awareness of warning signs for cancer in Britain, Cancer Causes Control 12 (2001) 33-37.

[8] J. Waller, K. Robb, S. Stubbings, A. Ramirez, U. Macleod, J. Austoker, S. Hiom, J. Wardle, Awareness of cancer symptoms and anticipated help seeking among ethnic minority groups in England, Br. J. Cancer 101 Suppl 2 (2009) S24-S30.

[9] S.C. FitzGerald, M. Al Sahaf, H. Furlong, K. Pennycooke, C. Healy, T.N. Walsh, Lack of awareness of oesophageal carcinoma among the public in Ireland, Ir. J. Med. Sci. 177(2) (2008) 151-4.

[10] E.A. Grunfeld, A.J. Ramirez, M.S. Hunter, M.A. Richards, Women's knowledge and beliefs regarding breast cancer, Br. J. Cancer 86(9) (2002) 1373-8.

[11] K. McCaffery, J. Wardle, J. Waller, Knowledge, attitudes, and behavioral intentions in relation to the early detection of colorectal cancer in the United Kingdom, Prev. Med. 36(5) (2003) 525-35.

[12] L. Rudberg, S. Nilsson, K. Wikblad, M. Carlsson, Testicular cancer and testicular selfexamination: knowledge and attitudes of adolescent Swedish men, Cancer Nurs. 28(4) (2005) 256-62.

[13] J. Wardle, J. Waller, N. Brunswick, M.J. Jarvis, Awareness of risk factors for cancer among British adults, Public Health 115(3) (2001) 173-4.

[14] R. West, M.N. Alkhatib, A. McNeill, R. Bedi, Awareness of mouth cancer in Great Britain, Br. Dent. J. 200(3) (2006) 167-9.

[15] Department of Health, Evaluation of the Bowel Cancer Awareness pilot in the South West and East of England: 31 January to 18 March 2011, London, 2012.

[16] L.J.L. Forbes, L. Atkins, A. Thurnham, J. Layburn, F. Haste, A.J. Ramirez, Breast cancer awareness and barriers to symptomatic presentation among women from different ethnic groups in East London, Br. J. Cancer 105(10) (2011) 1474-1479.

[17] A. Alborz, R. McNally, C. Glendinning, Access to health care for people with learning disabilities in the UK: mapping the issues and reviewing the evidence, J. Health Serv. Res. Policy 10(3) (2005) 173-82.

[18] G.L. Kreps, L. Sparks, Meeting the health literacy needs of immigrant populations, Patient Educ. Couns. 71(3) (2008) 328-32. 
[19] J. Hayden, R. Veith, S.M. Thomas, J.P. Austin, T. Moore, Changing cancer outcome: the role of LSUMC Minority-Based Clinical Community Oncology Program, The Journal of the Louisiana State Medical Society : official organ of the Louisiana State Medical Society 149(4) (1997) 131-133.

[20] S.M. Flanagan, B. Hancock, S.M. Flanagan, B. Hancock, 'Reaching the hard to reach'-lessons learned from the VCS (voluntary and community Sector). A qualitative study, BMC Health Serv. Res. 10 (2010) 92-92.

[21] National Institute for Health and Care Excellence, Behaviour Change: general approaches, 2007.

[22] M.W. Kreuter, R.J. Wray, Tailored and targeted health communication: strategies for enhancing information relevance, Am J Health Behav 27 Suppl 3 (2003) S227-32.

[23] S. McLachlan, G. Mansell, T. Sanders, S. Yardley, D. van der Windt, L. Brindle, C. ChewGraham, P. Little, Symptom perceptions and help-seeking behaviour prior to lung and colorectal cancer diagnoses: a qualitative study, Fam. Pract. 32(5) (2015) 568-77.

[24] A.S. Ahmad, N. Ormiston-Smith, P.D. Sasieni, Trends in the lifetime risk of developing cancer in Great Britain: comparison of risk for those born from 1930 to 1960, Br. J. Cancer 112(5) (2015) 943-7.

[25] Department of Health, Lung cancer early awareness campaigns, Policy Research Unit in Economic Evaluation of Health and Care Interventions: report, University of York, London, 2012, pp. 9-15.

[26] A.B. Michael S. Lewis-Beck, Tim Futing Liao, Snowball Sampling, The SAGE Encyclopedia of Social Science Research Methods (2004).

[27] Cancer Research UK, Cancer Awareness Measure (CAM) toolkit (v2.1), Kings College, London.

[28] Excel for Windows, Microsoft, Washington, 2010.

[29] SPSS Statistics for Windows, IBM Corporation, New York, 2011.

[30] Department of Health National Awareness Early Diagnosis Initiative, Public awareness of cancer in Britain: NAEDI report, London, 2009.

[31] S.L. Quaife, L.J.L. Forbes, A.J. Ramirez, K.E. Brain, C. Donnelly, A.E. Simon, J. Wardle, Recognition of cancer warning signs and anticipated delay in help-seeking in a population sample of adults in the UK, Br. J. Cancer 110 (2014) 12-18.

[32] R.E. Petty, J.T. Cacioppo, The elaboration likelihood model of persuasion, Adv. Exp. Soc. Psychol. 19 (1986) 123-205.

[33] R.E. Petty, J. Barden, S.C. Wheeler, The Elaboration Likelihood Model of persuasion: Developing health promotions for sustained behavioral change . in: R.J. DiClemente, R.A. Crosby, M.C. Kegler (Eds.), Emerging theories in health promotion practice and research, Jossey-Bass, California, 2009, pp. 185-214.

[34] M.R.B. Keighley, C. O'Morain, A. Giacosa, M. Ashorn, A. Burroughs, M. Crespi, M. Delvaux, Public awareness of risk factors and screening for colorectal cancer in Europe, Eur. J. Cancer Prev. 13(4) (2004) 257-262.

[35] I.A. Malik, S. Gopalan, Use of CAM results in delay in seeking medical advice for breast cancer, Eur. J. Epidemiol. 18(8) (2003) 817-22. 
[36] E. Power, J. Wardle, Change in public awareness of symptoms and perceived barriers to seeing a doctor following Be Clear on Cancer campaigns in England, Br. J. Cancer (2015) 15.

[37] C. Burgess, M.S. Hunter, A.J. Ramirez, A qualitative study of delay among women reporting symptoms of breast cancer, Br. J. Gen. Pract. (2001).

[38] R.A. Breslow, J.D. Sorkin, C.M. Frey, L.G. Kessler, Americans' knowledge of cancer risk and survival, Prev. Med. 26(2) (1997) 170-7.

[39] J. Wardle, K. Parmenter, J. Waller, Nutrition knowledge and food intake, Appetite 34(3) (2000) 269-75.

[40] F. Fylan, Screening for cervical cancer: a review of women's attitudes, knowledge, and behaviour, Br. J. Gen. Pract. 48(433) (1998) 1509-14.

[41] W. Eijzenga, E.M. Bleiker, D.E. Hahn, I. Kluijt, G.N. Sidharta, C. Gundy, N.K. Aaronson, Psychosocial aspects of hereditary Cancer (PAHC) questionnaire: development and testing of a screening questionnaire for use in clinical cancer genetics, Psychooncology. 23(8) (2014) 862-9.

[42] M. Trevino, L. Jandorf, Z. Bursac, D.O. Erwin, Cancer screening behaviors among Latina women: the role of the Latino male, J. Community Health 37(3) (2012) 694-700.

[43] I.B. Banks, P, Men and Primary care: Improving access and outcomes, Trends in urology \& Men's health.

[44] R.J. Volk, S.J. Spann, A.R. Cass, S.T. Hawley, Patient education for informed decision making about prostate cancer screening: a randomized controlled trial with 1-year followup, Ann. Fam Med 1(1) (2003) 22-8.

[45] M.C. Council, Don't be a cancer chancer campaign, Manchester 2009, Manchester, 2010.

[46] NHS Choices, Be Clear On Cancer, http://www.nhs.uk/be-clear-on-cancer/. 
Figure 1 - Participants' perceived barriers to seeking help before and after the intervention

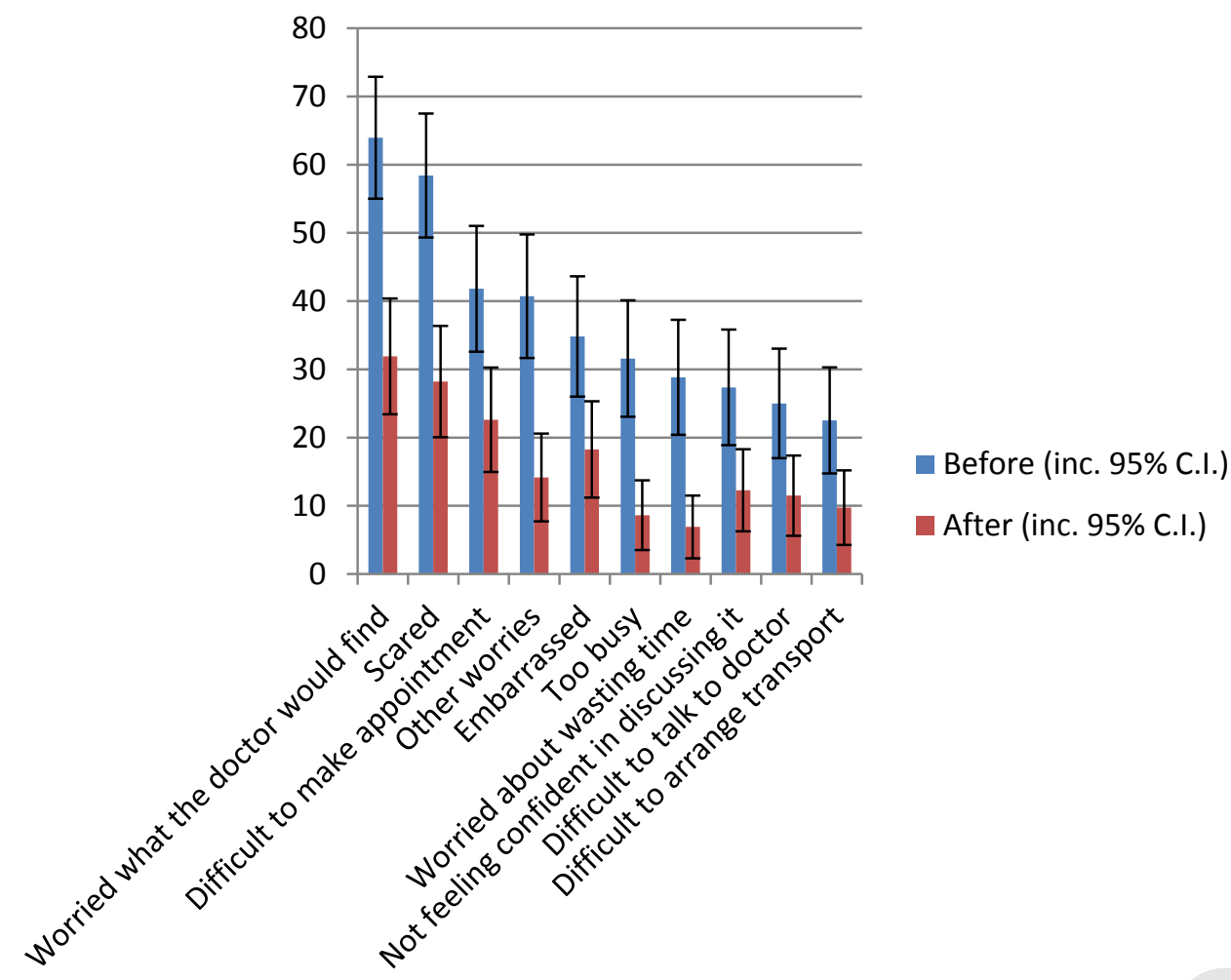


Table 1 - Socio-demographic characteristics of CAM respondents

\begin{tabular}{|c|c|}
\hline & $\mathbf{N}(\%)$ \\
\hline \multicolumn{2}{|l|}{ Gender } \\
\hline Male & 25 (21.0) \\
\hline Female & $94(79.0)$ \\
\hline \multicolumn{2}{|l|}{ Ethnicity } \\
\hline White British & $90(76.3)$ \\
\hline Other & $28(23.7)$ \\
\hline \multicolumn{2}{|l|}{ First Language } \\
\hline English & $107(90.7)$ \\
\hline Not English & $11(9.3)$ \\
\hline \multicolumn{2}{|l|}{ Age } \\
\hline 50 or above & $44(41.5)$ \\
\hline Below 50 & $62(58.5)$ \\
\hline \multicolumn{2}{|l|}{ Educational attainment } \\
\hline O-Level/GCSE (Grades A-C) or above & $75(79.8)$ \\
\hline Below O-level/GCSE (Grades A-C) & $19(20.2)$ \\
\hline \multicolumn{2}{|l|}{ Marital status } \\
\hline Married/living with partner & $41(35.0)$ \\
\hline Other & $76(65.0)$ \\
\hline \multicolumn{2}{|l|}{ Employment } \\
\hline Employed & $60(52.2)$ \\
\hline Other & $55(47.8)$ \\
\hline \multicolumn{2}{|l|}{ Cancer history } \\
\hline Has family/friend with cancer & $84(71.8)$ \\
\hline No history & $33(28.2)$ \\
\hline \multicolumn{2}{|l|}{ Registered with GP } \\
\hline Yes & $116(99.1)$ \\
\hline No & $1(0.9)$ \\
\hline
\end{tabular}


Table 2 - Recall and recognition responses to warning signs and risk factors of cancer

\begin{tabular}{|c|c|c|c|c|c|c|}
\hline & \multicolumn{3}{|c|}{ Recall } & \multicolumn{3}{|c|}{ Recognition } \\
\hline & $\begin{array}{c}\text { Before } \\
\mathrm{n}(\%)\end{array}$ & $\begin{array}{l}\text { After } \\
\text { n (\%) }\end{array}$ & McNemar Test & $\begin{array}{c}\text { Before } \\
n(\%)\end{array}$ & $\begin{array}{l}\text { After } \\
\text { n (\%) }\end{array}$ & McNemar Test \\
\hline \multicolumn{7}{|l|}{ Warning signs } \\
\hline Lump/swelling & $107(89.92)$ & $106(89.08)$ & $p>0.999$ & $114(98.28)$ & $116(100)$ & $p=0.625$ \\
\hline (Unexplained) pain & $62(52.10)$ & $72(60.50)$ & $p=0.212$ & $100(86.21)$ & $108(93.10)$ & $p=0.035$ \\
\hline $\begin{array}{l}\text { (Unexplained) } \\
\text { bleeding }\end{array}$ & $48(40.34)$ & $88(73.95)$ & $p<0.001$ & $99(85.34)$ & $114(98.28)$ & $p=0.001$ \\
\hline $\begin{array}{l}\text { (Persistent) } \\
\text { cough/hoarseness }\end{array}$ & $34(28.57)$ & $90(75.63)$ & $p<0.001$ & $80(68.97)$ & $112(96.55)$ & $p<0.001$ \\
\hline $\begin{array}{l}\text { (Persistent) change } \\
\text { in bowel/bladder } \\
\text { habits }\end{array}$ & $10(8.40)$ & $40(33.61)$ & $p<0.001$ & $99(85.34)$ & $114(98.28)$ & $p<0.001$ \\
\hline Difficulty swallowing & $1(0.84)$ & $7(5.88)$ & $p=0.070$ & $68(58.62)$ & $107(92.24)$ & $p<0.001$ \\
\hline $\begin{array}{l}\text { Change in } \\
\text { appearance of mole }\end{array}$ & 19 (15.97) & $42(35.29)$ & $p=0.001$ & $111(95.67)$ & $114(98.28)$ & $p=0.219$ \\
\hline $\begin{array}{l}\text { Sore that does not } \\
\text { heal }\end{array}$ & $2(1.68)$ & $5(4.20)$ & $p=0.453$ & $63(54.31)$ & $108(93.10)$ & $p<0.001$ \\
\hline $\begin{array}{l}\text { (Unexplained) } \\
\text { weight loss }\end{array}$ & 19 (15.97) & $76(63.87)$ & $p<0.001$ & $91(78.45)$ & $112(96.55)$ & $p<0.001$ \\
\hline & \multicolumn{3}{|c|}{ Recall* } & \multicolumn{3}{|c|}{ Recognition* } \\
\hline & $\begin{array}{c}\text { Before } \\
\mathrm{n}(\%)\end{array}$ & $\begin{array}{l}\text { After } \\
\text { n (\%) }\end{array}$ & McNemar Test & $\begin{array}{c}\text { Before } \\
\text { n (\%) }\end{array}$ & $\begin{array}{l}\text { After } \\
\mathrm{n}(\%)\end{array}$ & McNemar Test \\
\hline \multicolumn{7}{|l|}{ Risk Factors } \\
\hline Smoking & $40(33.6)$ & $39(32.8)$ & $p>0.999$ & $48(87.3)$ & $45(83.3)$ & $p=0.453$ \\
\hline Passive smoking & $1(0.8)$ & $0(0)$ & $p>0.999$ & $40(72.7)$ & 45 (84.9) & $p=0.180$ \\
\hline $\begin{array}{l}\text { Drinking alcohol } \\
\text { (alcohol intake) }\end{array}$ & $28(23.5)$ & $27(22.7)$ & $p>0.999$ & $23(41.8)$ & $39(73.6)$ & $p<0.001$ \\
\hline $\begin{array}{l}\text { Not eating enough } \\
\text { fruit and veg (Eating } \\
\text { less than } 5 \text { portions } \\
\text { of fruit and veg a } \\
\text { day) }\end{array}$ & $1(0.8)$ & $0(0)$ & $p>0.999$ & $17(30.9)$ & $32(61.5)$ & $p<0.001$ \\
\hline $\begin{array}{l}\text { Eating red or } \\
\text { processed meat } \\
\text { (once a day or } \\
\text { more) }\end{array}$ & & 0 & $p>0.999$ & $13(23.2)$ & 31 (59.6) & $p<0.001$ \\
\hline Being overweight & $3(2.5)$ & $9(7.6)$ & $p=0.031$ & $29(51.8)$ & $46(86.8)$ & $p<0.001$ \\
\hline $\begin{array}{l}\text { Getting } \\
\text { sunburnt/exposure } \\
\text { to the sun (Getting } \\
\text { sunburnt more than } \\
\text { once as a child) }\end{array}$ & $5(4.2)$ & $3(2.5)$ & $p=0.687$ & $28(50.9)$ & $34(65.4)$ & $p=0.096$ \\
\hline $\begin{array}{l}\text { Older age (Being } \\
\text { over } 70 \text { years old) }\end{array}$ & $1(0.8)$ & $9(7.6)$ & $p=0.008$ & $25(46.3)$ & $41(75.9)$ & $p<0.001$ \\
\hline $\begin{array}{l}\text { Family history } \\
\text { (Having a close } \\
\text { relative with cancer) }\end{array}$ & $15(12.6)$ & $20(16.8)$ & $p=0.383$ & $41(73.2)$ & $43(82.7)$ & $p=0.344$ \\
\hline
\end{tabular}




\begin{tabular}{|l|r|r|r|r|r|r|} 
Infection with HPV & $0(0)$ & $0(0)$ & $p>0.999$ & $15(27.8)$ & $29(53.7)$ & $p<0.001$ \\
\hline $\begin{array}{l}\text { Not doing enough } \\
\text { exercise/physical } \\
\text { activity (Doing less } \\
\text { than 30 mins of } \\
\text { moderate physical } \\
\text { activity 5 times a } \\
\text { week }\end{array}$ & & & & & & \\
\hline Diet & $5(4.2)$ & $0(0)$ & $p<0.001$ & $19(34.5)$ & $41(77.4)$ & $p<0.001$ \\
\hline
\end{tabular}

* NOTE - For risk factors, some participants were asked not to answer the question as risk factors were not covered as part of the intervention. No record was kept as to which respondents received these instructions, and so we cannot be sure of the $N$ number for these questions. For the recall questions, the denominator was kept as all questionnaires as we cannot be sure whether some could not recall any, whereas the denominator for the recognition values excluded missing values. 
Table 3 - McNemar Test for dichotomised responses to questions about barriers to visiting GPs regarding cancer symptoms before and after the intervention

\begin{tabular}{|c|c|c|c|c|c|c|c|c|}
\hline \multirow[b]{2}{*}{ Barriers to seeking help } & \multicolumn{3}{|c|}{ Before } & \multicolumn{3}{|c|}{ After } & \multirow[b]{2}{*}{$\begin{array}{l}\text { McNemar } \\
\text { Test }\end{array}$} & \multirow[b]{2}{*}{$\begin{array}{l}\text { Reduction } \\
\text { (\%) }\end{array}$} \\
\hline & $\begin{array}{l}\text { Yes } \\
\mathrm{n}(\%)\end{array}$ & $\begin{array}{c}\text { No } \\
\mathrm{n}(\%)\end{array}$ & $\mathbf{n}$ & $\begin{array}{l}\text { Yes } \\
\mathrm{n}(\%)\end{array}$ & $\begin{array}{c}\text { No } \\
\mathrm{n}(\%)\end{array}$ & $\mathbf{n}$ & & \\
\hline $\begin{array}{l}\text { Worried what the doctor } \\
\text { would find }\end{array}$ & $\begin{array}{r}71 \\
(63.96) \\
\end{array}$ & $\begin{array}{r}40 \\
(36.04) \\
\end{array}$ & 111 & $\begin{array}{r}37 \\
(31.9) \\
\end{array}$ & $\begin{array}{r}79 \\
(68.1) \\
\end{array}$ & 116 & $p<0.001$ & 32.06 \\
\hline Scared & $\begin{array}{r}66 \\
(58.41) \\
\end{array}$ & $\begin{array}{r}47 \\
(41.59) \\
\end{array}$ & 113 & $\begin{array}{r}33 \\
(28.21) \\
\end{array}$ & $\begin{array}{r}84 \\
(71.79) \\
\end{array}$ & 117 & $p<0.001$ & 30.2 \\
\hline Difficult to make appointment & $\begin{array}{r}46 \\
(41.82) \\
\end{array}$ & $\begin{array}{r}64 \\
(58.18) \\
\end{array}$ & 110 & $\begin{array}{r}26 \\
(22.61) \\
\end{array}$ & $\begin{array}{r}89 \\
(77.39) \\
\end{array}$ & 115 & $p<0.001$ & 19.21 \\
\hline Other worries & $\begin{array}{r}46 \\
(40.71) \\
\end{array}$ & $\begin{array}{r}67 \\
(59.29) \\
\end{array}$ & 113 & $\begin{array}{r}16 \\
(14.16) \\
\end{array}$ & $\begin{array}{r}97 \\
(85.84) \\
\end{array}$ & 113 & $p<0.001$ & 26.55 \\
\hline Embarrassed & $\begin{array}{r}39 \\
(34.82) \\
\end{array}$ & $\begin{array}{r}73 \\
(65.18) \\
\end{array}$ & 112 & $\begin{array}{r}21 \\
(18.26) \\
\end{array}$ & $\begin{array}{r}94 \\
(81.74) \\
\end{array}$ & 115 & $p<0.001$ & 16.56 \\
\hline Too busy & $\begin{array}{r}36 \\
(31.58) \\
\end{array}$ & $\begin{array}{r}78 \\
(68.42) \\
\end{array}$ & 114 & $\begin{array}{r}10 \\
(8.62) \\
\end{array}$ & $\begin{array}{r}106 \\
(91.38) \\
\end{array}$ & 116 & $p<0.001$ & 22.96 \\
\hline Worried about wasting time & $\begin{array}{r}32 \\
(28.83) \\
\end{array}$ & $\begin{array}{r}79 \\
(71.17) \\
\end{array}$ & 111 & $\begin{array}{r}8 \\
(6.9) \\
\end{array}$ & $\begin{array}{r}108 \\
(93.1) \\
\end{array}$ & 116 & $p<0.001$ & 21.93 \\
\hline $\begin{array}{l}\text { Not feeling confident in } \\
\text { discussing it }\end{array}$ & $\begin{array}{r}29 \\
(27.36) \\
\end{array}$ & $\begin{array}{r}77 \\
(72.64) \\
\end{array}$ & 106 & $\begin{array}{r}14 \\
(12.28) \\
\end{array}$ & $\begin{array}{r}100 \\
(87.72) \\
\end{array}$ & 114 & $p=0.004$ & 15.08 \\
\hline Difficult to talk to doctor & $\begin{array}{r}28 \\
(25) \\
\end{array}$ & $\begin{array}{r}84 \\
(75) \\
\end{array}$ & 112 & $\begin{array}{r}13 \\
(11.5) \\
\end{array}$ & $\begin{array}{r}100 \\
(88.5) \\
\end{array}$ & 113 & $p=0.003$ & 13.5 \\
\hline Difficult to arrange transport & $\begin{array}{r}25 \\
(22.52) \\
\end{array}$ & $\begin{array}{r}86 \\
(77.48) \\
\end{array}$ & 111 & $\begin{array}{r}11 \\
(9.73) \\
\end{array}$ & $\begin{array}{r}102 \\
(90.27) \\
\end{array}$ & 113 & $p=0.012$ & 12.79 \\
\hline
\end{tabular}


Table 3 - McNemar Test for dichotomised responses to questions about barriers to visiting GPs regarding cancer symptoms before and after the intervention

\begin{tabular}{|c|c|c|c|c|c|c|c|c|}
\hline \multirow[b]{2}{*}{ Barriers to seeking help } & \multicolumn{3}{|c|}{ Before } & \multicolumn{3}{|c|}{ After } & \multirow[b]{2}{*}{$\begin{array}{l}\text { McNemar } \\
\text { Test }\end{array}$} & \multirow[b]{2}{*}{$\begin{array}{l}\text { Reduction } \\
\text { (\%) }\end{array}$} \\
\hline & $\begin{array}{c}\text { Yes } \\
\mathrm{n}(\%) \\
\end{array}$ & $\begin{array}{c}\text { No } \\
\mathrm{n}(\%)\end{array}$ & $\mathbf{n}$ & $\begin{array}{c}\text { Yes } \\
\mathrm{n}(\%)\end{array}$ & $\begin{array}{c}\text { No } \\
\mathrm{n}(\%)\end{array}$ & $\mathbf{n}$ & & \\
\hline $\begin{array}{l}\text { Worried what the doctor } \\
\text { would find }\end{array}$ & $\begin{array}{r}71 \\
(63.96) \\
\end{array}$ & $\begin{array}{r}40 \\
(36.04) \\
\end{array}$ & 111 & $\begin{array}{r}37 \\
(31.9) \\
\end{array}$ & $\begin{array}{r}79 \\
(68.1) \\
\end{array}$ & 116 & $p<0.001$ & 32.06 \\
\hline Scared & $\begin{array}{r}66 \\
(58.41)\end{array}$ & $\begin{array}{r}47 \\
(41.59)\end{array}$ & 113 & $\begin{array}{r}33 \\
(28.21)\end{array}$ & $\begin{array}{r}84 \\
(71.79)\end{array}$ & 117 & $p<0.001$ & 30.2 \\
\hline Difficult to make appointment & $\begin{array}{r}46 \\
(41.82) \\
\end{array}$ & $\begin{array}{r}64 \\
(58.18) \\
\end{array}$ & 110 & $\begin{array}{r}26 \\
(22.61) \\
\end{array}$ & $\begin{array}{r}89 \\
(77.39) \\
\end{array}$ & 115 & $p<0.001$ & 19.21 \\
\hline Other worries & $\begin{array}{r}46 \\
(40.71) \\
\end{array}$ & $\begin{array}{r}67 \\
(59.29) \\
\end{array}$ & 113 & $\begin{array}{r}16 \\
(14.16) \\
\end{array}$ & $\begin{array}{r}97 \\
(85.84) \\
\end{array}$ & 113 & $p<0.001$ & 26.55 \\
\hline Embarrassed & $\begin{array}{r}39 \\
(34.82) \\
\end{array}$ & $\begin{array}{r}73 \\
(65.18) \\
\end{array}$ & 112 & $\begin{array}{r}21 \\
(18.26) \\
\end{array}$ & $\begin{array}{r}94 \\
(81.74) \\
\end{array}$ & 115 & $p<0.001$ & 16.56 \\
\hline Too busy & $\begin{array}{r}36 \\
(31.58) \\
\end{array}$ & $\begin{array}{r}78 \\
(68.42) \\
\end{array}$ & 114 & $\begin{array}{r}10 \\
(8.62) \\
\end{array}$ & $\begin{array}{r}106 \\
(91.38) \\
\end{array}$ & 116 & $p<0.001$ & 22.96 \\
\hline Worried about wasting time & $\begin{array}{r}32 \\
(28.83) \\
\end{array}$ & $\begin{array}{r}79 \\
(71.17)\end{array}$ & 111 & $\begin{array}{r}8 \\
(6.9) \\
\end{array}$ & $\begin{array}{r}108 \\
(93.1)\end{array}$ & 116 & $p<0.001$ & 21.93 \\
\hline $\begin{array}{l}\text { Not feeling confident in } \\
\text { discussing it }\end{array}$ & $\begin{array}{r}29 \\
(27.36) \\
\end{array}$ & $\begin{array}{r}77 \\
(72.64)\end{array}$ & 106 & $\begin{array}{r}14 \\
(12.28)\end{array}$ & $\begin{array}{r}100 \\
(87.72) \\
\end{array}$ & 114 & $p=0.004$ & 15.08 \\
\hline Difficult to talk to doctor & $\begin{array}{r}28 \\
(25) \\
\end{array}$ & $\begin{array}{r}84 \\
(75) \\
\end{array}$ & 112 & $\begin{array}{r}13 \\
(11.5) \\
\end{array}$ & $\begin{array}{r}100 \\
(88.5) \\
\end{array}$ & 113 & $p=0.003$ & 13.5 \\
\hline Difficult to arrange transport & $\begin{array}{r}25 \\
(22.52)\end{array}$ & $\begin{array}{r}86 \\
(77.48)\end{array}$ & 111 & $\begin{array}{r}11 \\
(9.73)\end{array}$ & $\begin{array}{r}102 \\
(90.27)\end{array}$ & 113 & $p=0.012$ & 12.79 \\
\hline
\end{tabular}

